\title{
Evaluation of Elevator Safety Based on Gray Relational Analysis
}

\author{
Xiao $\mathrm{Hu}^{1, a}$, Sixian Ding, ${ }^{2, b}$, Yongming Huang ${ }^{2, \mathrm{c}}$, Hang Zhang ${ }^{1, \mathrm{~d}}$ \\ ${ }^{1}$ Special Equipment Safety Supervision Inspection Institute of Jiangsu Province, Nanjing 210096, \\ China; \\ ${ }^{2}$ School of Automation, Southeast University, Nanjing 210096, China. \\ amailhuxiao@163.com, b15851866176@163.com, c94165742@qq.com, d6611710@qq.com
}

Keywords: elevator safety; state assessment; GRA; AHP; entropy weight method.

\begin{abstract}
In this paper, a new elevator operation reliability evaluation model based on the combination of Gray Relational Analysis (GRA) and Analytic Hierarchy Process (AHP) is proposed. In order to further overcome the shortage of indicators of equal rights and the lack of expert assignment via the original gray relational analysis method, AHP is used in this paper to determine the weight of each indicator in the proposed model, then GRA is used to get all indicators' gray relational degree between their current state and optimal state. The gray relational matrix is established and a quantitative assessment of elevator risk is achieved in the model. Finally, an example is used to show that the accuracy and feasibility of the proposed model.
\end{abstract}

\section{Introduction}

According to the statistics of the National Quality Inspection Bureau [1], the number of elevators in China has exceeded 200 million, and more than 400 million people take elevators every day. Therefore, the insurance of the safe operation of the elevator is indeed a big challenge for the elevator safety management [2].

In this paper, the elevator is regarded as a gray system. According to the analysis of the gray correlation degree between the indicators' current states and perfect states from four aspects of the Capsules system, traction system, door system and drive system, the main factors that affect the safety of the elevator can be obtained, and then each indicator's weight can be obtained using AHP method. Finally, the safety level of the elevator will be determined by analyzing the weighted gray relational degree of indicators.

\section{Evaluation Index System of Elevator Safety System}

The selected indicators should have the characteristics of reliability, sensitivity, independence and practicability. According to the above principles and the elevator technical standards[12], based on the study of the elevator safety by Xu J. [10] and Li L. [11], this paper constructs the evaluation index system of the elevator's car subsystem, traction system, door system and driving system , which is shown in Figure 1. In this paper, the indicators are recorded as $X(k), k=1,2, \ldots, 17$.

\section{Safety Evaluation based on GRA}

\subsection{Gray Relational Analysis}

The gray system theory was put forward in the early 1980s. Cao S. [13] uses the GRA method to evaluate the coal mine safety. M.Lu and K.Wevers[14] use the GRA method to 


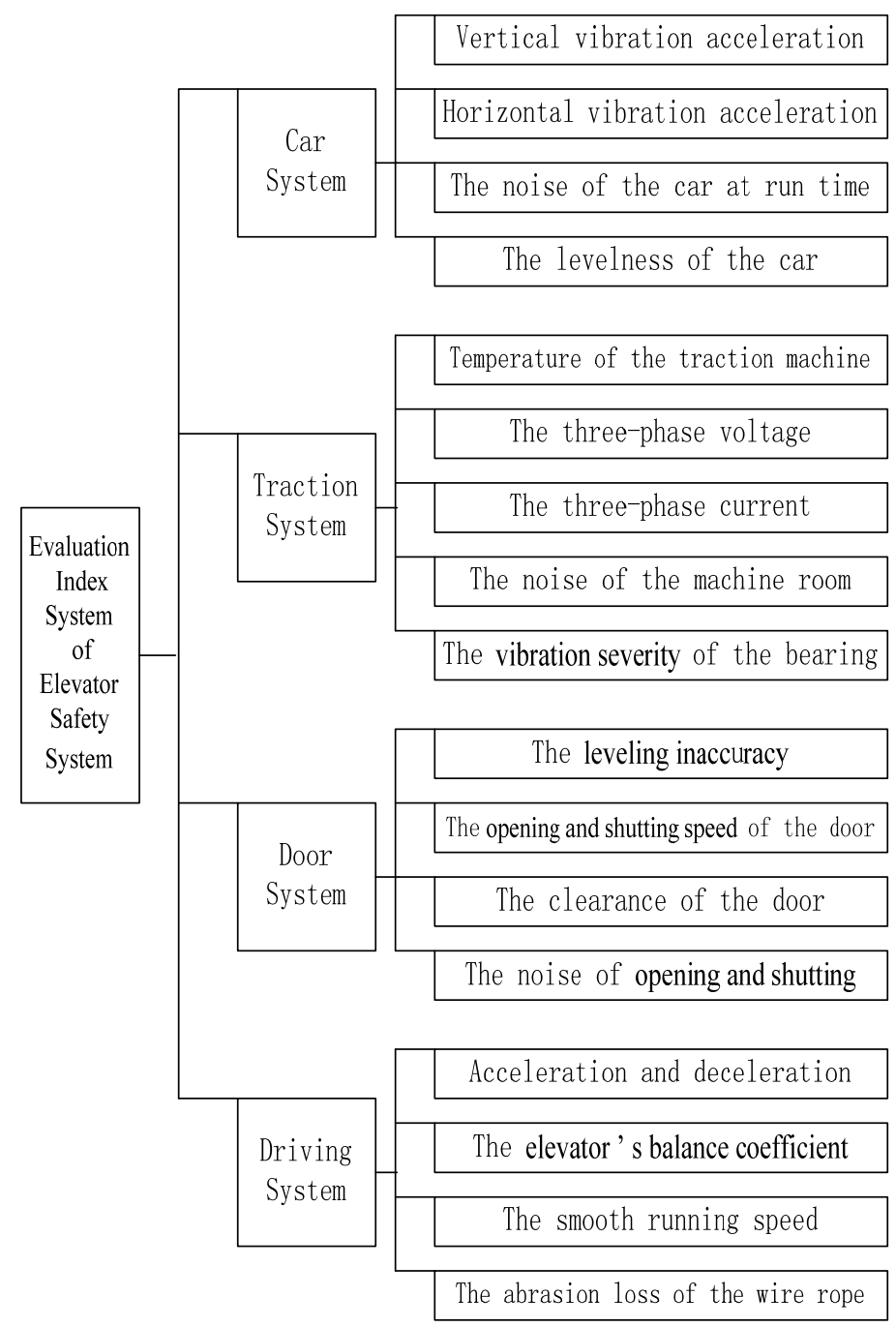

Fig.1 Evaluation indexes system of elevator

evaluate the safety measures which are applied in traffic system. Gu H. and Song B. [15] study the effectiveness of the weapon system based on the GRA method. The steps to obtain the gray correlation coefficient is as follows.

1) Determining the reference sequence and comparison sequence

The reference sequence that reflects the characteristics of the system is recorded as $X_{0}(k)=\left\{X_{0}(1), X_{0}(2), \ldots, X_{0}(n)\right\}, k=1,2, \ldots, n$. Supposing the number of comparison sequences is $\mathrm{m}$ and the number of indicators of each sequence is $\mathrm{n}$. These comparison sequences are recorded as $X_{1}(k), X_{2}(k), X_{3}(k), \ldots, X_{m}(k), k=1,2, \ldots, n$.

1) Dimensionless treatment of the initial data

In order to make the data comparable, it is necessary to eliminate their dimension. In this paper, interval valued transformation method is used to process the data. The formula is as follows.

$$
Y_{i}(k)=\frac{\max _{i} X_{i}(k)-X_{i}(k)}{\max _{i} X_{i}(k)-\min _{i} X_{i}(k)},(i=1,2, \ldots, m ; k=1,2, \ldots, n)
$$

2) Obtaining the difference order

$$
\begin{gathered}
\Delta_{i}(k)=\left|x^{\prime}(k)-x_{i}^{\prime}(k)\right| \\
\Delta_{i}=\left(\Delta_{i}(1), \Delta_{i}(2), \ldots, \Delta_{i}(n)\right)
\end{gathered}
$$

where $\mathrm{K}$ is the data sequence of the $\mathrm{i}$-th influencing factor.

3) Obtaining the largest difference and the smallest difference

$$
M=\max _{i} \max _{k} \Delta_{i}(k), \quad m=\min _{i} \min _{k} \Delta_{i}(k)
$$

4) Obtaining the correlation coefficient between the k-th element and $\mathrm{X} 0(\mathrm{X} 1)$. 


$$
\xi_{i}(k)=\frac{m+\rho M}{\Delta_{i}(k)+\rho M}[\rho \in(0,1) ; k=1,2, \ldots, n ; i=1,2, \ldots, m]
$$

where $^{\rho}$ is the identification coefficient, whose value interval is $[0,1]$. According to the study of different elevator cases, we obtain the most suitable identification coefficient is 0.5 , that is, $\rho=0.5$.

\subsection{Analytic Hierarchy Process}

AHP [17] combines the qualitative and quantitative analysis. It constructs a hierarchical structure model and decomposed each influencing factor into several levels. Then it compares the effects of the indicators of the same level on the upper level's indicators with each other, and construct the judgment matrix. Then the largest characteristic root of the judgment matrix and the corresponding characteristic vector is solved and the weights of indicators are calculated. Finally, the judgment matrix will be test for its consistency. If the test is not passed, the judgment matrix needs to be readjusted.

In this paper, the judgment matrix is constructed according to the 1-9 scale method. The car system, the traction system, the door system and the drag system is taken as an example to obtain their weights for the importance of the elevator safety.

Table 1. Meaning of 1-9 scale method

\begin{tabular}{cc}
\hline Scaling & Meaning \\
\hline 1 & Two factors have the same importance. \\
5 & The former factor is slightly more important than the latter. \\
7 & The former factor is generally more important than the latter. \\
9 & The former factor is more important than the latter. \\
$2,4,6,8$ & The former factor is much more important than the latter. \\
The median of the above adjacent comparisons. \\
The reciprocal of $1,2, \ldots, 9$ & The importance of the latter factor relative to the former.
\end{tabular}

1) Then the most reasonable judgment matrix $A$ is obtained according to the 1-9 scale method. The matrix A is shown as follows.

$$
A=\left[\begin{array}{cccc}
1 & \frac{1}{2} & \frac{1}{7} & \frac{1}{5} \\
2 & 1 & \frac{1}{3} & \frac{1}{6} \\
7 & 3 & 1 & 2 \\
5 & 6 & \frac{1}{2} & 1
\end{array}\right]
$$

2) The largest characteristic root $\lambda_{\max }$ and the corresponding characteristic vectors $\alpha_{\max }$ is calculated according to the formula $A \alpha=\lambda \alpha$. The results are as follows.

$\lambda_{\max }=4.1830, \alpha_{\max }=(0.1002,0.1752,0.7677,0.6082)$

3) The inspection coefficient CR of the judgment matrix is calculated according to the formula(6). If $\mathrm{CR}<0.1$ can be satisfied, it means the matrix A has a satisfactory consistency. Otherwise, it is necessary to readjust the judgment matrix. The inspection coefficient CR of the matrix is calculated as follows.

$$
C R=\frac{C I}{R I}, \quad C I=\frac{\lambda_{\max }-n}{n-1}
$$

where $n$ is the dimension of the matrix, $R I$ is the mean.

random consistency index. Table 2 shows how to obtain their values.

Table 2. Values of average stochastic consistency index RI

\begin{tabular}{ccccccccccccc}
\hline Order & 1 & 2 & 3 & 4 & 5 & 6 & 7 & 8 & 9 & 10 & 11 & $\ldots$ \\
\hline RI & 0 & 0 & 0.58 & 0.89 & 1.12 & 1.26 & 1.36 & 1.41 & 1.45 & 1.49 & 1.52 & $\ldots$ \\
\hline
\end{tabular}

In this paper, $n=4$, the value of CI and RI can be obtained according to Table 2 . The results are shown as follows.

$$
C I=\frac{\lambda_{\max }-n}{n-1}=\frac{4.1830-4}{4-1}=0.0610, R I=0.89 \text {. }
$$


The inspection coefficient of the judgment matrix A is calculated as follows.

$$
C R=\frac{C I}{R I}=\frac{0.0610}{0.89}=0.0685<0.1 \text {. }
$$

It can be seen that the matrix A has satisfactory consistency.

4) After the normalization of $\alpha_{\max }$, the weights of the four systems can be obtained as follows. $w=(0.0607,0.1061,0.4649,0.3683)$

\subsection{The Calculation of Gray Correlation Degree based on Weight}

The correlation coefficient is the correlation degree between the comparison sequence and the reference sequence at each point and the number of it is more than one. In order to make an overall comparison, it is necessary to concentrate the correlation coefficients of each point into a single value, that is, their average. The weighted correlation degree is calculated as follows.

$$
R_{0 i}(k)=\frac{1}{n} \sum_{k=1}^{n} w_{k} \xi_{0 i}(k), i=1,2, \ldots, m ; k=1,2, \ldots, n, \sum_{k=1}^{n} w_{k}=1
$$

where $w_{k}$ is the weight of the k-th evaluation index.

According to the comparison and analysis of the indicators' correlation degree, the safety evaluation of the elevator can be carried out. In general, the greater the correlation degree is, the better safety condition the elevator is in. Then a more objective and comprehensive evaluation on the safety condition of each elevator can be conducted, which provides a good foundation for the future elevator safety management.

\section{Case Analysis}

Three low-speed passenger elevators in a building in Nanjing are taken as examples. The indicators' values of the three elevators are measured and the classification of the indicators is shown in Figure 1. Then the weight of each index is calculated according to AHP method. Because of space limitations, the results are listed directly, and the calculation results of the weights and the measured values of the three elevators' indicators are integrated in Table 3. The last column of the table is the optimal value of each index of the elevator.

4.1 Determination of the Reference Sequence and the Comparison Sequence

As can be seen from Table 3 , the reference sequence is shown as $X_{0}=(0.2,0.15,20,0,50,380,30,30,0.45,10,0.25,3,30,1,0.45,1.5,5)$.

\subsection{Dimensionless Treatment of the Data}

According to the formula (1), the dimensionless treatment of the four types of data in the matrix $\mathrm{X}$ can be completed. The results are obtained as follows. 
Table 3. The chart of comprehensive assessment in the elevator

\begin{tabular}{|c|c|c|c|c|c|c|c|}
\hline \multirow{2}{*}{$\begin{array}{l}\text { First-class } \\
\text { indicators }\end{array}$} & \multirow[b]{2}{*}{ Weight } & \multirow[b]{2}{*}{ Second-class indicators } & \multirow[b]{2}{*}{ Weight } & \multicolumn{4}{|c|}{ The sequence of the elevator safety index } \\
\hline & & & & $\begin{array}{c}\text { Elevator } \\
\mathrm{A}\end{array}$ & $\begin{array}{c}\text { Elevator } \\
\mathrm{B}\end{array}$ & $\begin{array}{c}\text { Elevator } \\
\mathrm{C}\end{array}$ & $\begin{array}{l}\text { Optimu } \\
\text { m value }\end{array}$ \\
\hline \multirow{4}{*}{ Car system } & \multirow{4}{*}{0.0607} & $\begin{array}{c}\text { Vertical vibration } \\
\text { acceleration/(m/s2) }\end{array}$ & 0.2945 & 0.259 & 0.299 & 0.3 & 0.2 \\
\hline & & $\begin{array}{c}\text { Horizontal vibration } \\
\text { acceleration/(m/s²) }\end{array}$ & 0.2575 & 0.169 & 0.18 & 0.17 & 0.15 \\
\hline & & $\begin{array}{l}\text { The noise of the car at run } \\
\text { time/dB }\end{array}$ & 0.1858 & 19.6 & 25 & 26 & 20 \\
\hline & & $\begin{array}{c}\text { The levelness of the } \\
\text { car/mm }\end{array}$ & 0.2622 & 0.31 & 0.5 & 0.45 & 0 \\
\hline \multirow{5}{*}{$\begin{array}{l}\text { Traction } \\
\text { system }\end{array}$} & \multirow{5}{*}{0.1061} & $\begin{array}{c}\text { Temperature of the traction } \\
\text { machine } /{ }^{\circ} \mathrm{C}\end{array}$ & 0.2145 & 55 & 46 & 48 & 50 \\
\hline & & The three-phase voltage/V & 0.1912 & 389.7 & 388 & 388.5 & 380 \\
\hline & & The three-phase current/A & 0.1958 & 33.5 & 32 & 32.4 & 30 \\
\hline & & $\begin{array}{l}\text { The noise of the machine } \\
\text { room/dB }\end{array}$ & 0.1544 & 33 & 25 & 27 & 30 \\
\hline & & $\begin{array}{l}\text { The vibration severity of the } \\
\text { bearing } /(\mathrm{mm} / \mathrm{s})\end{array}$ & 0.2441 & 1.02 & 1.25 & 1.05 & 0.45 \\
\hline \multirow{4}{*}{$\begin{array}{l}\text { Door } \\
\text { system }\end{array}$} & \multirow{4}{*}{0.4649} & $\begin{array}{c}\text { The leveling } \\
\text { inaccuracy/mm }\end{array}$ & 0.3586 & 13.4 & 16.2 & 18 & 10 \\
\hline & & $\begin{array}{l}\text { The opening and shutting spee } \\
\mathrm{d} \text { of the door } /(\mathrm{m} / \mathrm{s})\end{array}$ & 0.2434 & 0.24 & 0.29 & 0.35 & 0.25 \\
\hline & & $\begin{array}{c}\text { The clearance of the } \\
\text { door } / \mathrm{mm}\end{array}$ & 0.1795 & 4.58 & 5.1 & 5.3 & 3 \\
\hline & & $\begin{array}{c}\text { The noise of opening and } \\
\text { shutting/dB }\end{array}$ & 0.2185 & 40.5 & 38 & 33 & 30 \\
\hline \multirow{4}{*}{$\begin{array}{l}\text { Drivi1ng } \\
\text { system }\end{array}$} & \multirow{4}{*}{0.3683} & $\begin{array}{c}\text { Acceleration and } \\
\text { deceleration } /\left(\mathrm{m} / \mathrm{s}^{2}\right)\end{array}$ & 0.2524 & 0.84 & 0.95 & 1.1 & 1 \\
\hline & & Balance coefficient & 0.1801 & 0.46 & 0.5 & 0.55 & 0.45 \\
\hline & & $\begin{array}{l}\text { The smooth running } \\
\text { speed/(m/s) }\end{array}$ & 0.2793 & 1.26 & 1.6 & 1.8 & 1.5 \\
\hline & & $\begin{array}{l}\text { The abrasion loss of the wire } \\
\text { rope } \%\end{array}$ & 0.2882 & 6.9 & 7.5 & 8.9 & 5 \\
\hline
\end{tabular}

$Y_{01}=\left[\begin{array}{llll}0.9900 & 0.9925 & 0 & 1\end{array}\right] \quad Y_{02}=\left[\begin{array}{lllll}0.8695 & 0 & 0.9221 & 0.9221 & 1\end{array}\right]$

$Y_{03}=\left[\begin{array}{llll}0.6723 & 1 & 0.9076 & 0\end{array}\right] \quad Y_{04}=\left[\begin{array}{lllll}0.8791 & 1 & 0.7692 & 0\end{array}\right]$

$Y_{1}=\left[\begin{array}{llll}0.9954 & 1 & 0 & 0.9927 \\ 0.9952 & 1 & 0 & 0.9871 \\ 0.9950 & 1 & 0 & 0.9892\end{array}\right] \quad Y_{2}=\left[\begin{array}{lllll}0.8611 & 0 & 0.9164 & 0.9177 & 1 \\ 0.8843 & 0 & 0.9205 & 0.9386 & 1 \\ 0.8788 & 0 & 0.9191 & 0.9330 & 1\end{array}\right]$

$Y_{3}=\left[\begin{array}{llll}0.6731 & 1 & 0.8922 & 0 \\ 0.5781 & 1 & 0.8724 & 0 \\ 0.4594 & 1 & 0.8484 & 0\end{array}\right] \quad Y_{4}=\left[\begin{array}{llll}0.9410 & 1 & 0.8758 & 0 \\ 0.9357 & 1 & 0.8429 & 0 \\ 0.9341 & 1 & 0.8503 & 0\end{array}\right]$

\subsection{Getting the Difference Order According to the Formula (2) and (3)}

The calculated results are as follows.

$$
\begin{aligned}
\Delta_{1} & =\left[\begin{array}{llll}
0.0054 & 0.0075 & 0 & 0.0073 \\
0.0052 & 0.0075 & 0 & 0.0129 \\
0.0050 & 0.0075 & 0 & 0.0108
\end{array}\right] \Delta_{2}=\left[\begin{array}{lllll}
0.0084 & 0 & 0.0057 & 0.0044 & 0 \\
0.0148 & 0 & 0.0016 & 0.0165 & 0 \\
0.0093 & 0 & 0.0030 & 0.0109 & 0
\end{array}\right] \\
\Delta_{3} & =\left[\begin{array}{llll}
0.0008 & 0 & 0.0154 & 0 \\
0.0942 & 0 & 0.0352 & 0 \\
0.2129 & 0 & 0.0592 & 0
\end{array}\right] \quad \Delta_{4}=\left[\begin{array}{llll}
0.0619 & 0 & 0.1066 & 0 \\
0.0566 & 0 & 0.0737 & 0 \\
0.0550 & 0 & 0.0811 & 0
\end{array}\right]
\end{aligned}
$$

Finally, the largest and the smallest difference of these four matrices are obtained as $m_{1}=0, M_{1}=0.0129 ; m_{2}=0, M_{2}=0.0165 ; m_{3}=0, M_{3}=0.2129 ; m_{4}=0, M_{4}=0.1066$. 


\subsection{Safety Assessment and Analysis}

Taking the content of Jiangsu Province elevator safety assessment as the standard, the gray correlation degree is divided into five levels, which is shown in Table 4.

Table 4. Classification and assessment conclusion of elevator safety levels

\begin{tabular}{cccccc}
\hline & \multicolumn{5}{c}{ Elevator safety level } \\
\cline { 2 - 6 } & $\mathrm{A}$ & $\mathrm{B}$ & $\mathrm{C}$ & $\mathrm{D}$ & $\mathrm{E}$ \\
\hline $\begin{array}{c}\text { Conclusion of } \\
\text { the correlation } \\
\text { degree } \\
\text { assessment }\end{array}$ & $R \geq 0.8$ & $0.7 \leq R<0.8$ & $0.6 \leq R<0.7$ & $0.45 \leq R<0.6$ & $R<0.45$ \\
\cline { 2 - 5 } & Very good & good & general & attention & serious \\
\hline
\end{tabular}

\subsubsection{Primary Safety Assessment}

The correlation coefficient matrix of the four subsets is calculated according to the formula (5). The results are as follows.

$$
\begin{aligned}
& \xi_{1}=\left[\begin{array}{llll}
0.5443 & 0.4624 & 1 & 0.4691 \\
0.5536 & 0.4624 & 1 & 0.3333 \\
0.5633 & 0.4624 & 1 & 0.3739
\end{array}\right] \quad \xi_{2}=\left[\begin{array}{lllll}
0.4955 & 1 & 0.5914 & 0.6522 & 1 \\
0.3579 & 1 & 0.8376 & 0.3333 & 1 \\
0.4701 & 1 & 0.7333 & 0.4308 & 1
\end{array}\right] \\
& \xi_{3}=\left[\begin{array}{llll}
0.9925 & 1 & 0.8736 & 1 \\
0.5305 & 1 & 0.7515 & 1 \\
0.3333 & 1 & 0.6426 & 1
\end{array}\right] \quad \xi_{4}=\left[\begin{array}{llll}
0.4627 & 1 & 0.3333 & 1 \\
0.4850 & 1 & 0.4197 & 1 \\
0.4922 & 1 & 0.3966 & 1
\end{array}\right]
\end{aligned}
$$

It can be seen from Table 3 that the weight of each index in car system is as follows. $\omega=\left[\begin{array}{llll}0.2945 & 0.2575 & 0.1858 & 0.2622\end{array}\right]$

According to the formula (7), the correctional degree of the car system indicators is obtained as $R_{1}=\xi_{1} \bullet \omega=\left[\begin{array}{lll}0.5882 & 0.5553 & 0.5688\end{array}\right]^{T}$.

The primary evaluation can be carried out. According to Table 4, it can be seen that the safety status of the car system of the three elevators is "attention". The order of the correlation degree of them is $A>C>B$, that is, the order of their car systems' safety status from high to low is “ $A, C, B$ ". The same procedure can be easily adapted to obtain the correctional degree of the traction system indicators. The result is shown as $R_{2}=\left[\begin{array}{lll}0.7597 & 0.7298 & 0.7482\end{array}\right]^{T}$.

According to Table 4, it can be seen that the safety status of the traction system of the three elevators is "good". The order of correlation degree of them is $A>C>B$, that is, the order of their traction systems' safety status from high to low is “A, C, B”.

The correctional degree of the door system indicators is $R_{3}=\left[\begin{array}{lll}0.9746 & 0.7870 & 0.6968\end{array}\right]^{T}$.

According to Table 4, it can be seen that the safety status of the door system of the elevator A is "very good" and that of elevator B is "good" and that of elevator C is "general". The order of correlation degree of them is, that is, the order of their door systems' safety status from high to low is “A, B, C”.

The correctional degree of the driving system index is $R_{4}=\left[\begin{array}{lll}0.6782 & 0.7079 & 0.7033\end{array}\right]^{T}$.

According to Table 4, it can be seen that the safety status of the driving system of the elevator $\mathrm{A}$ is "general" and that of elevator B and C is "good". The order of correlation degree of them is " $B>C>A$ ", that is, the order of their driving systems' safety status from high to low is "B,C, A".

Based on the above evaluation results, it is possible to perform a reasonable safety treatment for each system of the elevators.

\subsubsection{Secondary Safety Evaluation}

It can be seen from the primary evaluation that there may be both the best and the worst status parts in the same elevator, which is difficult to reflect the overall safety of the elevator. Therefore, we carry out the secondary comprehensive evaluation of the whole elevator system. According to Table 3, the weight of the first level indicators of the elevator is obtained as

$$
\omega=\left[\begin{array}{llll}
0.0607 & 0.1061 & 0.4649 & 0.3683
\end{array}\right]^{T} \text {. }
$$

The integrated correctional degree of the three elevators is calculated as 


$$
R=\left[\begin{array}{llll}
R_{1} & R_{2} & R_{3} & R_{4}
\end{array}\right] \bullet \omega=\left[\begin{array}{lll}
0.8192 & 0.7377 & 0.6969
\end{array}\right]^{T} .
$$

According to Table 4, it can be seen that the overall evaluation result of the elevator A is "very good" and that of the elevator B is "good" and that of the elevator C is "general". The order of correlation degree of these three elevators is " $A>B>C$ ", that is, the order of their safety status from high to low is “A, B, C”. What's more, the correlation degree of the elevator C is 0.6969 , which shows that the safety work should be intensified to detect and eliminate the hidden dangers in the elevator C. The safety conditions of the three elevators' car systems are all "attention", which shows we should take the appropriate measures for the weak link of them. The safety status of the driving system of the elevator A and that of the door system of the elevator C is "general", which shows they also should be checked for safety.

Above evaluation results are consistent with the actual situation, which reflects that the elevator evaluation model proposed in this paper based on the gray relational analysis is scientific and practical.

\section{Conclusion}

In this paper, in order to meet the need of the elevator testing and safety inspection, the car system, traction system, door system and driving system is selected as the first-class indicators to establish the elevator safety evaluation system and the evaluation model based on GRA theory.

The essence of the gray relational analysis is quantitatively calculating the correlation degree between each comparison sequence and reference sequence. In this method, a big sample size and a typical distribution of the sample is not necessary, which makes up for the lack of the mathematical statistical methods and overcomes the defects that there are too many qualitative indicators in the fuzzy comprehensive evaluation method. In addition, this method does not have a large amount of calculation, which is an intuitive and reliable evaluation method.

\section{Acknowledgements}

This paper is supported by the National Natural Science Foundation of China (61503081, 61473079) and Jiangsu Province Natural Science Foundation Youth Project (BK20140649).

\section{References}

[1]. General Administration of Quality Supervision, Inspection and Quarantine of the People's Republic of China Special equipment accident report 2014[R]. 2015.

[2]. Peng Heng. Effective measures to improve elevator safety [J]. Urban construction theory research, 2014(14):117-119.

[3]. 95/16/EC(Lifts), European Parliament and Council Directive 95/16/EC of 29 June 1995 on the approximation of the laws of the Member States relating to lifts [Z].

[4]. LI Lijing. A Study on the Measurement System and Technology of Fault Diagnosis for Elevators[D].

Tianjin:Tianjin University, 2013.

[5]. XU Jinhai. Research on security risk assessment system for in-use elevators[D]. Hangzhou: Zhejiang University, 2012.

[6]. GB10058-2009. Specification for electric lifts[S]. 2009.

[7]. Cao Shugang, Xv Ameng, Liu Yanbao, Zhang Liqiang. Comprehensive Assessment of Security in Coal Mines Based on Grey Relevance Analysis[J]. Journal of Mining and Safety Engineering,2007(2):141-145.

[8]. M.Lu and K.Wevers. "Application of grey relational analysis for evaluating road traffic safety measures: advanced driver assistance systems against infrastructure redesign", IET Intelligent Transport Systems, vol. 1, pp. 3-14, April 2007. 
[9]. Gu Hui, Song Bifeng. "Study on effectiveness evaluation of weapon systems based on grey relational analysis and TOPSIS", Journal of Systems Engineering and Electronics, vol. 20, pp. 106-111, January 2012.

[10]. ZHUANG Chunji, WANG Zhirong, ZHANG Yu, et.al. Study evaluation model for the large amusement

[11]. rides based on the AHP-grey fuzzy[J]. Journal of Safety and Environment, 2015, 15(2):4246. 